\title{
A New Era of Machinery: Will the Accumulation of Capital Grow and Labor Intensity Decrease?
}

\author{
Askar Akaev \\ Moscow State University
}

Andrei Rudskoi

Peter the Great St. Petersburg Polytechnic University

Askar Sarygulov

Saint Petersburg State University of Economics

Valentin Sokolov

Saint Petersburg State University of Economics

\begin{abstract}
In order to forecast the macroevolution of the contemporary developed societies it appears essential to take into account the dynamics of a number of economic and technological indicators. In the present paper we undertake such an attempt. Almost ten years after the start of the last economic crisis, the world economy is looking for the most effective plans for recovery. Such recovery is often associated with the fourth industrial revolution, in which the technological factor becomes a key driver of development. However, like any technological breakthrough, it will bring not only 'roses of prosperity' but 'prickly thorns' of disappointment as well. The key challenges will be the provision of a new quality of economic growth and addressing the associated employment problem. In this paper, we attempt to show the trends in the ratio between capital and output, as well as the possible effects on employment in the industrialized countries and China until 2050. We used a modified production function with labor-saving technological progress. It is shown that by 2050 the capital-output ratio will not undergo significant changes, and in case of a rejection of institutional reforms and legislative diversification of new types of labor activity in different segments of the economy, there may be a decrease in the number of employed by an average of 20 per cent.
\end{abstract}

Social Evolution \& History, Vol. 18 No. 1, March 2019 67-93

(C) 2019 'Uchitel' Publishing House

DOI: $10.30884 / \mathrm{seh} / 2019.01 .04$ 


\section{INTRODUCTION}

In order to forecast the macroevolution of the contemporary developed societies it appears essential to take into account the dynamics of a number of economic and technological indicators. Such an attempt is undertaken in the present paper.

Despite the considerable efforts made by financial regulators to overcome the consequences of the 2008-2009 crisis, the economies of industrially developed countries show sluggish growth. In the case of the US economy, this was described as 'secular stagnation' (Summers 2014). Researchers who analyzed more than ten years of stagnation in the Japanese economy cited low efficiency of capital use as a reason (Ando, Christeris, and Miyagawa 2003; Hayashi 2006). The same process was named 'Stagnation Traps' (Benigno and Fornaro 2015), when under conditions of pessimistic expectations, the gap between large volumes of production and low growth rates can coexist. In their joint study, the Japanese and Korean economists consider the extremely low rate of capital expenditures for development as the reason for the stagnation of the Japanese economy.

Thus, there is a clear trend that has been defined in economic policy to overcome stagnation: stimulation of aggregate demand, a policy of maintaining a low interest rate, new investments in the economy and a number of other regulatory measures. At the same time, another way has been outlined to solve the problem of economic stagnation: the search for new technological solutions that could qualitatively change the entire economic landscape and give a new impetus to development. Recommendations for the development strategy of Industry 4.0 for German manufacturers (Kagermann, Wahlster and Helbig 2013), and two American concepts: Industrial Internet (Evans and Annunziata 2012) and Internet of Things (Swan 2012) should be noted here. The famous work on artificial intelligence, published in 2003 (Russel and Norvig 2003) laid the foundation for the industrial development of systems with artificial intelligence. At the World Economic Forum in 2016, K. Schwab initiated a broad discussion on the Fourth Industrial Revolution (Schwab 2016). Hence, one can easily notice an obvious accumulation of the necessary 'critical mass' of new knowledge and technologies that, like an explosion, can create new conditions for development, and this new 'critical mass of knowledge and technologies' can be defined as a new machine era.

Obviously, its development will require significant amounts of capital and expenditure on maintaining human resources. The subject of our further consideration will be two questions: what kind of capital / output ratio will take place and what is likely to happen in the employment 
market when new intelligent machine systems, global computer networks and markets create conditions for both free job search and for partial replacement of human knowledge with intelligent machines?

\section{SOME INITIAL ASSUMPTIONS}

Nicholas Kaldor (1961) has formulated five empirical regul arities, known as 'stylized facts', which are valid in the long term, when the consequences of various economic and financial shocks and crises are smoothed out. Some of these laws have remained valid so far and there is reason to believe that they will continue to act in the twentyfirst century, at least in the first half. For our study, the following three empirical laws of Kaldor (Kaldor 1961) are of interest:

1. The ratio of physical capital to output is almost constant.

2. The shares of labor and physical capital in the national income growth are almost constant.

3. According to the Kondratiev cycles theory at the downward stage of the $6^{\text {th }}$ Large cycle (2018-2050) the effect of capital saturation should come and one must actually assume that the accumulation of capital will take place not through an exponential function, but through a logistic one.

The first of these regularities can be formalized as follows:

$$
Y=\kappa \cdot K, \kappa=\text { const, }
$$

where $\kappa$ is the coefficient of capital return. We proceed from the premise that Equation (1) can be observed in the first half of the twentyfirst century. This directly follows from the results obtained by Thomas Piketty and set forth in his work 'Capital in the twenty-first Century' (Piketty 2014). Indeed, T. Piketty demonstrated that in the developed countries (USA, Great Britain, Germany, France, etc.) the ratio between capital $(K)$ and output $(Y)$ in the twentieth century, returned to values close to those observed at the end of the nineteenth century (Piketty 2014: 124, 125, 150, 159).

Between the eighteenth and nineteenth centuries, this ratio, representing the capital intensity $\beta=\kappa^{-1}=K / Y$, in the leading European states was quite stable and amounted $\beta \cong 7$ in France and the UK, and $\beta \cong 6.5$ in Germany (Piketty 2015: 135,153 ). In the US, this ratio reached quasi-stability at the beginning of the twentieth century at the level of $\beta \cong 4.5$, and then, starting from the mid-twentieth century, stabilized at the level of $\beta \cong 4$ (Piketty 2014).

As we can see, the changes in capital intensity in the United States were of a very limited scale in contrast with Western Europe, i.e. Kaldor's respective pattern for the United States also worked in the twen- 
tieth century. Piketty explains the return of capital intensity in the twenty-first century to a high level close to the indices observed in the eighteenth and nineteenth centuries by the transition to a regime of slow economic growth (Piketty 2014: 171). In this regard, Piketty predicts that in global terms the capital intensity $(\beta)$, which has already approached the 5 mark and reached the 1910 level, will later be around 6 in the middle of the twenty-first century and will reach 7 by the end of the twenty-first century. In our opinion, a significant increase in capital will actually take place, but the ratio $(\beta)$ will remain practically unchanged, which we will show further on the basis of model calculations.

As for the second of the above-mentioned Kaldor regularities, presumably, it will no longer be observed in the twenty-first century, as the share of capital in GDP growth will steadily increase which does not contradict the results that Piketty obtained.

\section{MODEL}

At the heart of our model is the production function with labor-saving (labor-intensive) technical progress:

$$
\widetilde{Y}=K^{\alpha} \cdot(A \cdot L)^{1+\sigma-\alpha},
$$

where $\tilde{Y}$ - theoretical volume of gross domestic product (GDP); $K-$ physical capital; $L$ - number of employees in the economy; $A$ - technical progress; $\alpha$ - share of capital in GDP growth; $\sigma$ - parameter characterizing the increasing return on the scale of production $(\sigma \geq 0)$. As it is known (Arthur 1996), the emergence and expansion of the knowledge economy and science-intensive high-tech industries was accompanied by the emergence of a trend of increasing returns in developed economies.

In the long term, the capital intensity is directly related to the level of savings $(S)$ in the country's economy and average growth rates $(g)$ of its gross domestic product $(Y)$ :

$$
\beta=\kappa^{-1}=\frac{s}{g},
$$

Piketty considers the relation (3) as the second basic law of capitalism. This law is asymptotic: in the long run, capital intensity $\beta$ tends to the equilibrium level determined by the ratio $\beta=s / g$. It is not difficult to see that this relation follows from Harrod-Domar's theory of economic growth and is unstable in the dynamic aspect. Thus, Equation (1) will be decisive for the production function (2). Consequently, the accumulation of capital and new revolutionary technologies and 
innovations will become the dominant driving force affecting economic development in the first half of the twenty-first century.

The growth of capital was the most important feature of capitalism in the nineteenth and twentieth centuries, and according to Piketty, in the twenty-first century this process will only accelerate.

Let us consider the laws of capital accumulation of the twentyfirst century. The dynamics of capital growth is determined by the equation of capital accumulation:

$$
\dot{K}(t)=I(t)-\mu \cdot K(t),
$$

where $I(t)$ - industrial investment, $\mu$ - capital consumption. Since, $I(t)=s \cdot Y(t)$, equation (4) is transformed to the form:

$$
K(t)=s \cdot Y(t)-\mu \cdot K(t) .
$$

Taking into account the basic equality (1), from (5) we obtain the final equation for the accumulation of capital:

$$
K(t)=(s \cdot \kappa-\mu) \cdot K(t) .
$$

The solution of this simplest differential equation has the form:

$$
K(t)=K_{0} \cdot \exp \left[(s \cdot \kappa-\mu) \cdot\left(t-T_{0}\right)\right] .
$$

Thus, under the assumptions of (1), there will be an exponential growth of the accumulated volume of productive capital in the twentyfirst century.

However, according to the theory of Kondratiev cycles, the effect of saturation of capital should emerge at its downward stage. Realistically, one must assume that the accumulation of capital will take place according to the logistic law:

$$
K(t)=\frac{K_{m}}{1+\left(\frac{K_{m}}{K_{0}}-1\right) \cdot \exp \left[-v_{\kappa} \cdot\left(t-T_{0}\right)\right]},
$$

where $K_{0}$ and $K_{\mathrm{m}}$ are initial and maximum values of accumulated capital within the $6^{\text {th }}$ Kondratiev cycle (2018-2050); $v_{\kappa}$ is the parameter characterizing the rate of capital accumulation.

Parameters $K_{\mathrm{m}}$ and $v_{\mathrm{\kappa}}$ in the formula (8) should be determined from the condition that the growth trajectories of accumulated capital (7) and (8) coincide in the upstream segment of $6^{\text {th }}$ Kondratiev cycle (2018-2034). Therefore, it is very important to accurately predict the values of the parameters $S, \kappa$ and $\mu$ in formula (7).

Furthermore, it is required to define the type and model of technological progress in production function (2). First of all, it should be 
noted that the basic innovations of the $6^{\text {th }}$ Kondratiev's cycle are general-purpose technologies (GPTs) with the potential of a wide application and distribution throughout national economies (Akaev and Rudskoi 2016). These technologies may help accelerate the accumulation of capital and are able to launch a long-term economic growth, starting from a protracted slow growth in the early 2020s and the subsequent acceleration in 2025-2040.

The growth rate can accelerate on condition that technological progress grows gradually and quickly enough to overcome the limiting restrains of accumulated capital. In the new conditions of accelerated accumulation of capital (8) it is most natural to adopt the type of technical progress associated with the amount of knowledge, skills and experience acquired in the process of practical work on new equipment, which depends on the amount of capital involved, i.e. a model of training in the process of production necessity, proposed by Kenneth Arrow in 1962 (Arrow 1962), will take place:

$$
\begin{aligned}
& \text { a) } A=K^{\theta} \\
& \text { b) } A=\left(\frac{K}{L}\right)^{\theta}, 0<\theta \leq 1,
\end{aligned}
$$

where $\theta$ is parameter characterizing the effectiveness of training. Arrow (1962) estimated the value of the parameter $\theta$ for the aviation industry to be approximately equal to 0.7 . Such high values of $\theta$ are characteristic for high-tech industries. For traditional sectors of the economy, assume values $\theta=0.3$. For most modern economies, the following inequality seems to be valid: $0.1<\theta<0.7$.

Moreover, as K. Arrow showed, the knowledge obtained in the process of production activity is freely distributed among the workers, i.e. there is an effect of spreading knowledge, while other companies get the effect of this process for free, as the external effect of raising the level of capital-labor ratio.

In the coming decades, the ratio (9b) will be more appropriate, since capital-labor capacity $(K / L)$ of the workplace will grow due to a simultaneous growth of capital and reduction of employment. In fact, the increase in capital in the twenty-first century will occur in conditions where the growth of fixed capital outpaces the dynamics of the labor force. Besides, the nature of capital expansion will change qualitatively in the twenty-first century during the $6^{\text {th }}$ Kondratiev cycle and a broad replacement of skilled labor (especially of medium qualification) with capital expressed by advanced robots and computers with artificial intelligence elements will start. 
How can we establish a functional relationship between the growth of capital intensity and the changes in the distribution of GDP growth between labor and capital? Piketty recommends using the first fundamental law of capitalism for this purpose (Piketty 2014):

$$
\alpha=r \cdot \beta,
$$

where $\alpha$ is the share of capital in GDP growth; $r$ is the rate of return on capital; $\beta$ is the capital intensity. The rate of return on capital $(r)$ was 5-6 per cent in the eighteenth-nineteenth centuries, grew to 78 per cent in the mid-twentieth century and then fell to $4-5$ per cent at the turn of the twentieth and twenty-first centuries (Piketty 2014). The share of capital in the GDP growth of the Western European countries amounted 35-40 per cent in the nineteenth century, in the midtwentieth century it fell to 20-25 per cent, and by the beginning of the twenty-first century it rose to 25-30 per cent (Piketty 2014). Piketty assumes that the share of capital in the national income can reach 3040 per cent by the middle of the twenty-first century on the world scale, that is a level close to the indicators of the eighteenth-nineteenth centuries, and possibly surpass them with an average return on capital of 4-5 per cent (Piketty 2014). In economic history, this has already happened: the growth of this indicator by 10 percentage points from 35-40 per cent at the turn of the eighteenth-nineteenth centuries to $45-50$ per cent was observed in the mid-nineteenth century (Piketty 2014).

We already noted that Kondratiev Cycles make the growth trajectory of the share of capital in GDP growth $\alpha$ become close to the logistic one:

$$
\alpha=\frac{\alpha_{m}}{1+\left(\frac{\alpha_{m}}{\alpha_{0}}-1\right) \exp \left[-v_{\alpha}\left(t-T_{0}\right)\right]},
$$

where $\alpha_{0}$ and $\alpha_{m}$ are the share of capital in GDP growth at the beginning and end of the $6^{\text {th }}$ Kondratiev cycle (2018 and 2050); $v_{\alpha}$ is the rate of increase in the share of capital. Piketty predicts that the value of $\alpha_{m}$ will exceed $\alpha_{0}$ by ten percent.

Thus, we have defined formulas (1), (8), (9b) and (11), which describe the development trends of high-yielding economies in the first half of the twenty-first century. Using these formulas, we can obtain the equations from the basic production formula (2) for calculating the predictive dynamics of the main economic variables $-Y, L$ and $A$. To this end, we substitute formulas (1) and (9b) in the production function (2). As a result, we get: 
a) $Y(t)=\kappa \cdot K(t)$
b) $q_{y}=\frac{\dot{Y}}{Y}=q_{k}=\frac{\dot{K}}{K}$
c) $L(t)=\kappa^{\frac{1}{(1-\theta)(1+\sigma-\alpha)}} \cdot K(t)^{\frac{1-\alpha-\theta \cdot(1+\sigma-\alpha)}{(1-(1+\sigma-\alpha)}} ;$
d) $A(t)=\left(\frac{K}{L}\right)^{\theta}=\kappa^{-\frac{\theta}{(1-\theta) \cdot(1+\sigma-\alpha)}} \cdot K(t)^{\frac{\theta \sigma}{(1-\theta) \cdot(1+\sigma-\alpha)}}$.

The dynamics of the accumulation of capital $K(t)$ is described by a logistic function (8):

$$
K(t)=\frac{K_{m}}{1+\left(\frac{K_{m}}{K_{0}}-1\right) \exp \left[-v_{\kappa} \cdot\left(t-T_{0}\right)\right]} .
$$

In the formulas (12) value of $\alpha$ is changed along the trajectory (11):

$$
\alpha(t)=\frac{\alpha_{m}}{1+\left(\frac{\alpha_{m}}{\alpha_{0}}-1\right) \exp \left[-v_{\alpha} \cdot\left(t-T_{0}\right)\right]} .
$$

As can be seen from formula (12b), the rate of economic growth will be determined solely by the intensity of capital accumulation and will not depend on the decline in employment. Taking (13) into account, we have:

$$
q_{y}=\frac{\dot{K}}{K}=v_{k} \cdot \frac{K(t)}{K_{(m)}} \cdot\left(\frac{K_{m}}{K_{0}}-1\right) \cdot \exp \left[-v_{k} \cdot\left(t-T_{0}\right)\right] .
$$

For countries where there is a constant or decreasing returns to scale $(\sigma=0)$ equations (12) will take the following form:
a) $Y(t)=\kappa \cdot K(t)$;
b) $q_{y}=q_{k}$
c) $L(t)=\kappa^{\frac{1}{(1-\theta)(1-\alpha)}} \cdot K(t)$;
d) $A(t)=\kappa^{-\frac{\theta}{(1-\theta) \cdot(1-\alpha)}}$.

\section{INITIAL DATA AND MODEL CALCULATIONS RESULTS}

To verify the model for all five countries - the US, UK, France, Japan and China, we used data from the World Bank (http://data.worldbank. org/) and from the University of Groningen (http://febpwt.webhosting. rug.nl/).

As for the empirical indicators of capital intensity (Table 2, Fig. 2) and capital retirement rates (Table 3, Fig. 3), they are listed below.

We can note that the data in Table 2 and the data used in the calculations coincide with data from other sources (Miyagawa, Takizawa and Tonogi 2016). 
Table 1

Savings rate as percentage of GDP (parameter $S$ )

\begin{tabular}{|l|c|c|c|c|c|}
\hline & US & UK & France & Japan & China \\
\hline 1970 & 21.5 & 30.0 & & & \\
\hline 1980 & 22.2 & 26.1 & 24.3 & & 35.5 \\
\hline 1990 & 18.8 & 19.6 & 21.0 & & 38.4 \\
\hline 2000 & 20.7 & 16.7 & 23.8 & 30.0 & 36.5 \\
\hline 2010 & 15.2 & 13.2 & 20.2 & 25.1 & 51.5 \\
\hline 2015 & 19.2 & 12.9 & 20.7 & 27.0 & 47.9 \\
\hline
\end{tabular}

Source: http://data.worldbank.org/indicator/NY.GNS. ICTR.ZS

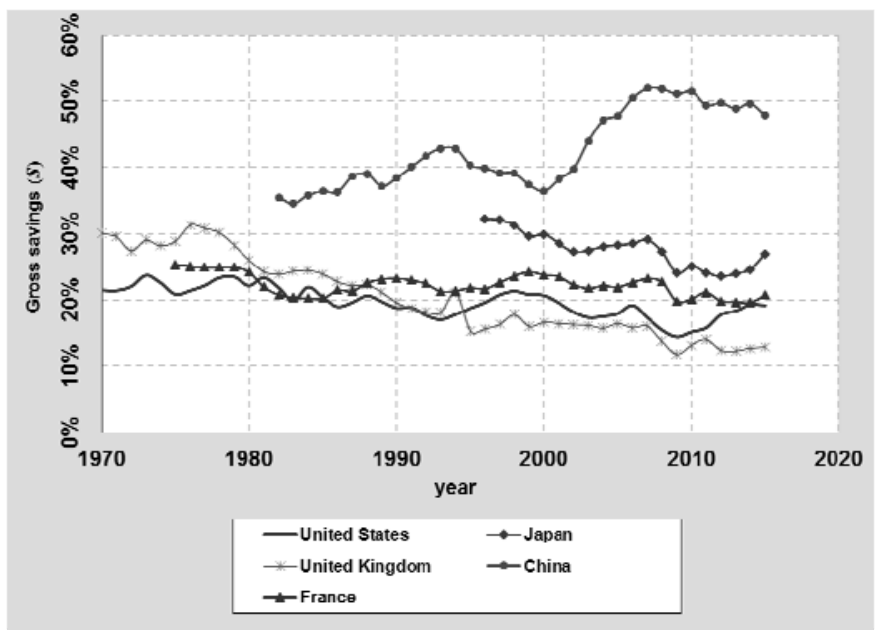

Fig. 1. Rate of savings as \% of GDP (parameter $S$ )

Table 2

Ratio of physical capital to GDP (parameter $\beta$ )

\begin{tabular}{|c|c|c|c|c|c|}
\hline & US & UK & France & Japan & China \\
\hline 1950 & 3.27 & 4.18 & 3.19 & 0.36 & 1.07 \\
\hline 1960 & 3.37 & 4.19 & 3.07 & 0.34 & 1.26 \\
\hline 1970 & 3.28 & 4.64 & 3.22 & 0.40 & 1.45 \\
\hline 1980 & 3.31 & 4.96 & 3.80 & 1.11 & 1.91 \\
\hline 1990 & 3.16 & 4.66 & 4.05 & 2.01 & 2.19 \\
\hline 2000 & 2.96 & 4.41 & 4.19 & 3.43 & 2.75 \\
\hline 2010 & 3.19 & 4.46 & 4.66 & 3.83 & 3.40 \\
\hline 2015 & 3.10 & 4.30 & 4.82 & 3.86 & 3.94 \\
\hline
\end{tabular}

Source: http://febpwt.webhosting.rug.nl/Dmn/AggregateXs/PivotShow\#. 


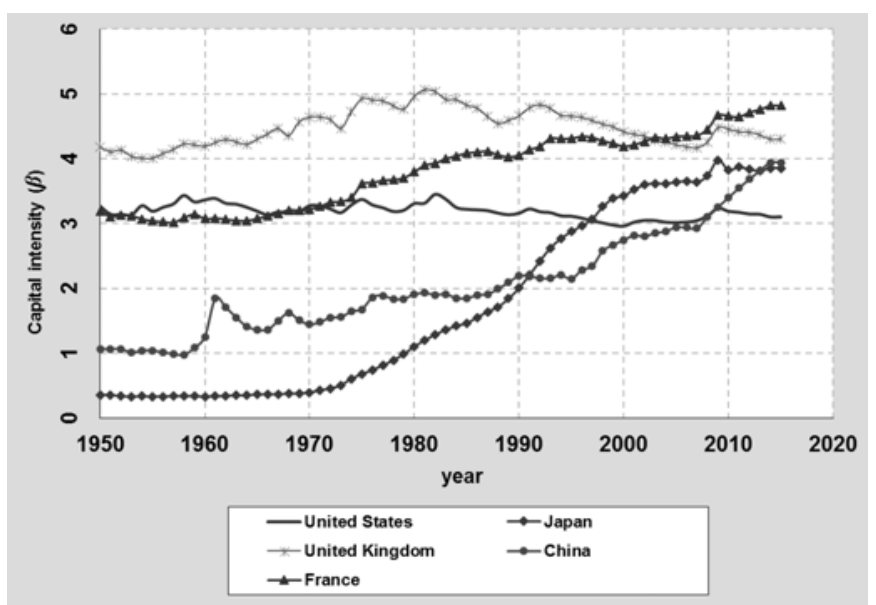

Fig. 2. Ratio of physical capital to GDP (parameter $\beta$ )

Capital consumption rates as \% of GDP (parameter $\mu$ )

\begin{tabular}{|c|c|c|c|c|c|}
\hline & USA & UK & France & Japan & China \\
\hline 1970 & 12.7 & 11.0 & 12.3 & 15.7 & 7.4 \\
\hline 1980 & 14.9 & 15.6 & 14.7 & 15.1 & 9.4 \\
\hline 1990 & 15.0 & 15.2 & 15.0 & 17.5 & 9.8 \\
\hline 2000 & 14.5 & 12.7 & 14.9 & 20.0 & 14.5 \\
\hline 2010 & 15.8 & 12.9 & 17.4 & 21.0 & 19.7 \\
\hline 2015 & 15.3 & 13.3 & 17.6 & 21.5 & 23.0 \\
\hline
\end{tabular}

Source: http://data.worldbank.org/indicator/NY.GNS.ICTR.ZS.

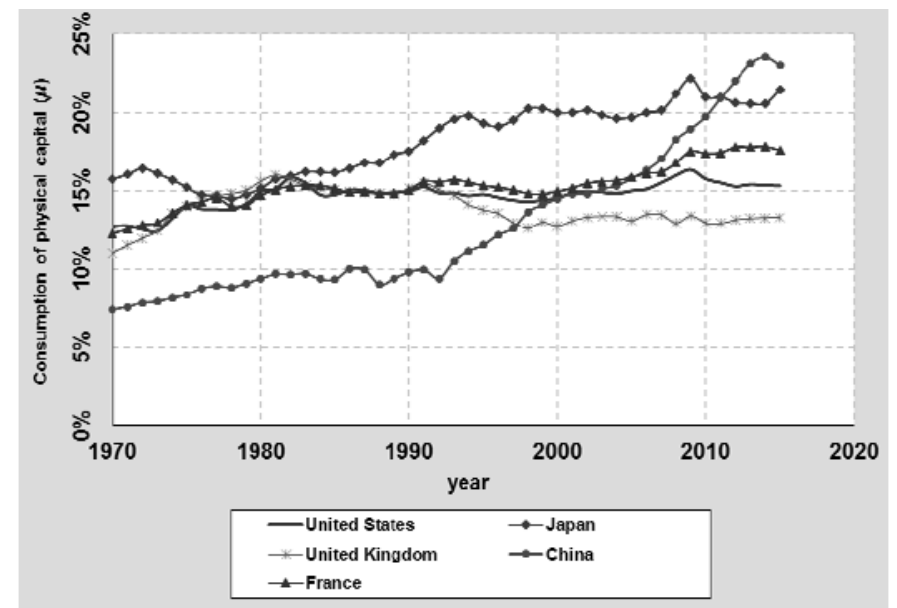

Fig. 3. Capital depreciation rates as \% of GDP (parameter $\mu$ ) 
The above retrospective values of parameters $S, \beta$ and $\mu$ are accepted as a guide for carrying out the calculations in the model within the forecast zone.

In the process of preliminary processing of the initial data, the behavior of the model parameters in the retrospective period (19502015) was investigated. On the basis of the production function (2), a dynamic assessment of the share of GDP growth factors was performed. In this case, the 'sliding window' method was used, in which the entire retrospective period was divided into separate sub-periods each lasting 30 years.

As an example, the approximation of the production function (2) for the sub-period 1985-2015 for the US economy is shown below (Fig. 4).

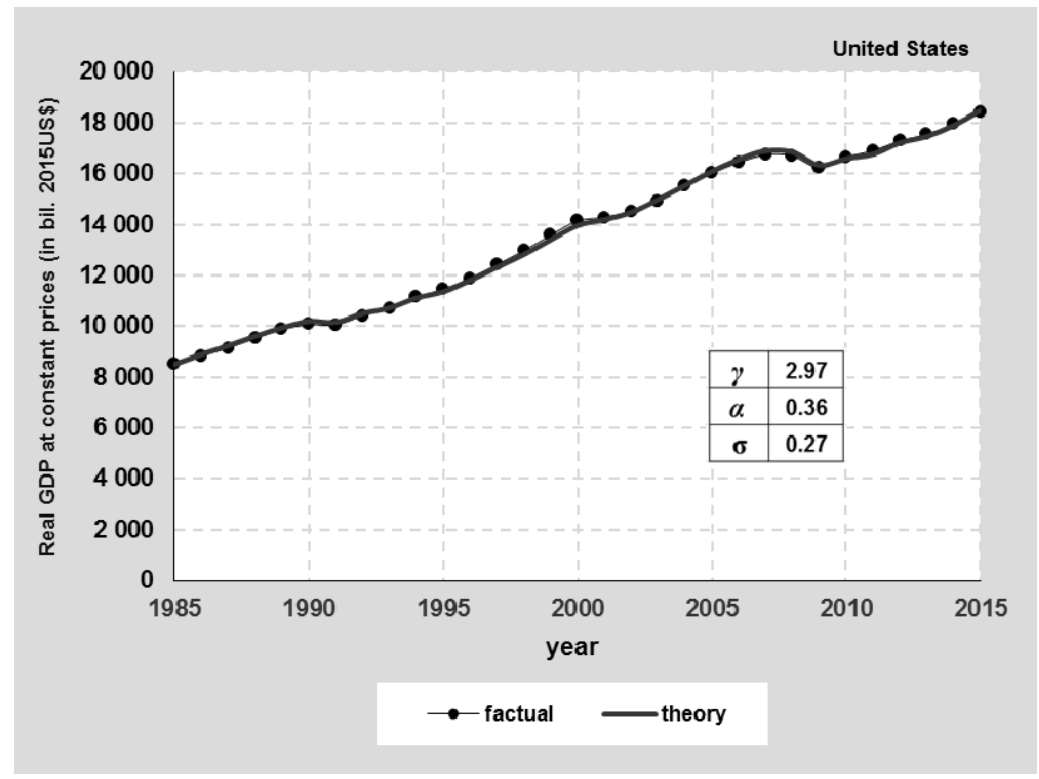

Fig. 4. Estimation of the parameters of the production function, 1985-2015 (2)

The generalization of the full set of calculations made it possible to obtain a dynamic picture of the changing parameters of the production function (2) in the retrospective period. Fig. 5 shows the dynamics of the share of factors in GDP growth for the US economy. These data coincide with data from other sources (Poterba 1998). 


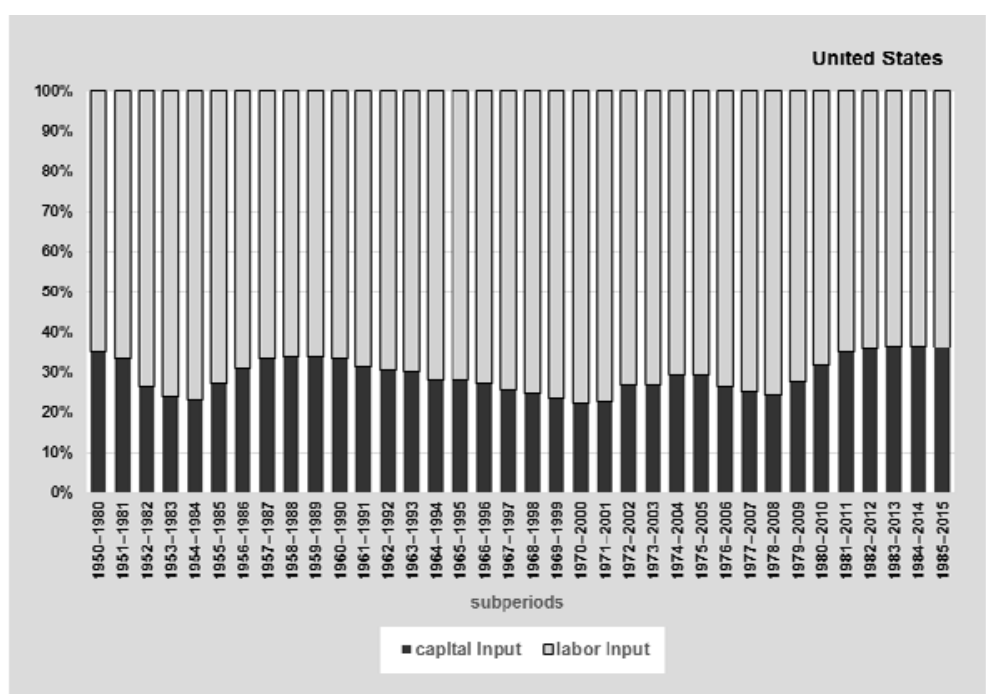

Fig. 5. Change in the share of factors in GDP growth in the US

Fig. 6 illustrates the time variation of the recoil parameter $(\sigma)$.

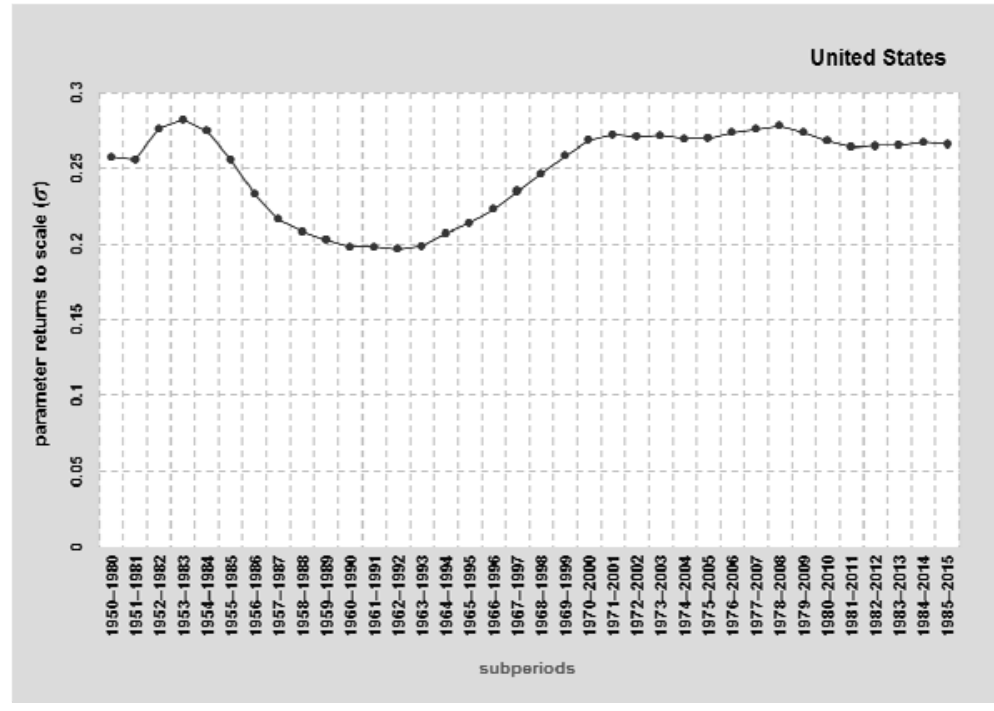

Fig. 6. Change in the parameter returns to scale for the USA

Directly predicted model calculations begin with an estimate of the dynamics of the volume of capital according to formulas (7) and (8). 


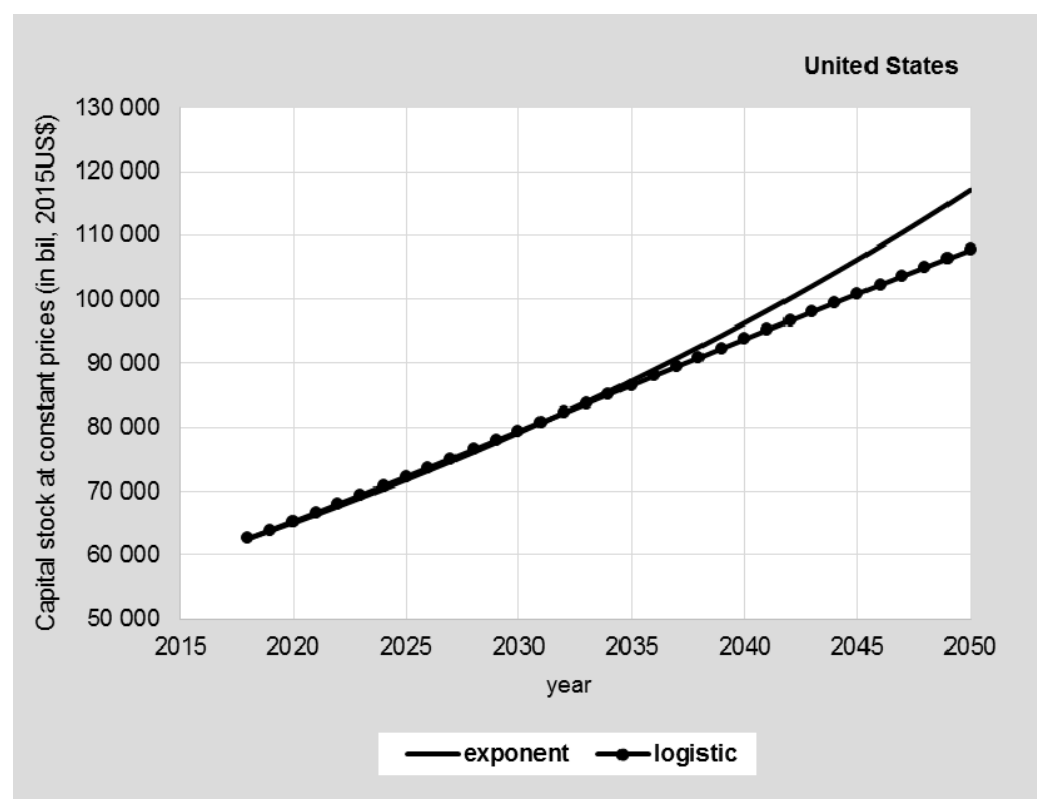

Fig. 7. Variations of the forecast for volume of US physical capital

Estimated parameters

for exponential function for logistic function

\begin{tabular}{|c|c|}
\hline$T_{0}$ & 2018 \\
\hline$K_{0}$ & 62568 \\
\hline$S$ & 0.18 \\
\hline$\kappa$ & 0.32 \\
\hline$\mu$ & 0.038 \\
\hline
\end{tabular}

\begin{tabular}{|c|c|}
\hline$K_{m}$ & 170000 \\
\hline$v_{K}$ & 0.034 \\
\hline
\end{tabular}

The complete idea of the change in the volume of the US productive capital over a hundred-year period is shown in Fig. 8. 


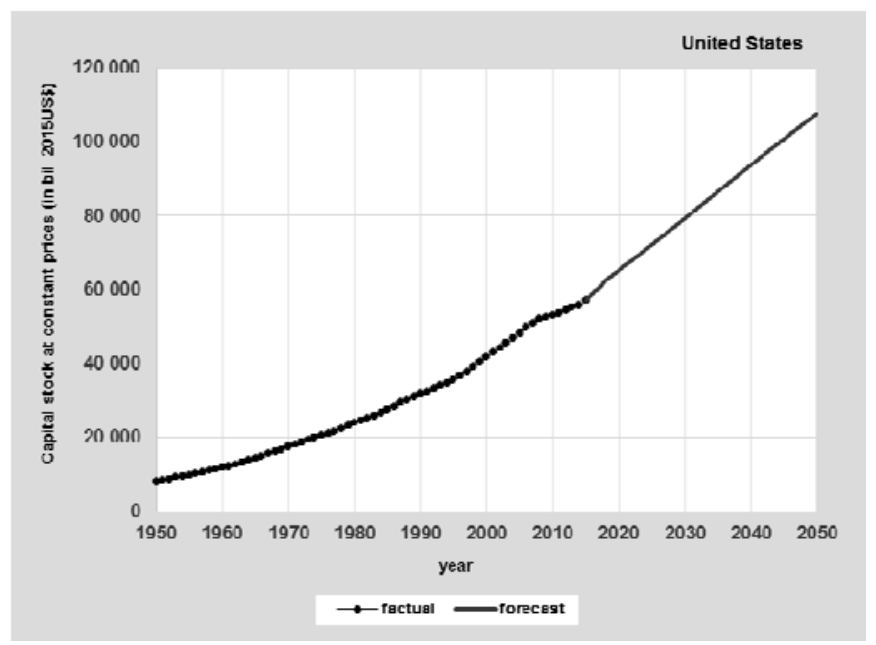

Fig. 8 Dynamics of the volume of physical capital of the US (in comparable prices of 2015. In the forecast zone, the dynamics of the volume of capital is taken along the logistical trajectory)

Furthermore, according to the formula (1), the GDP volume is predicted (Fig. 9)

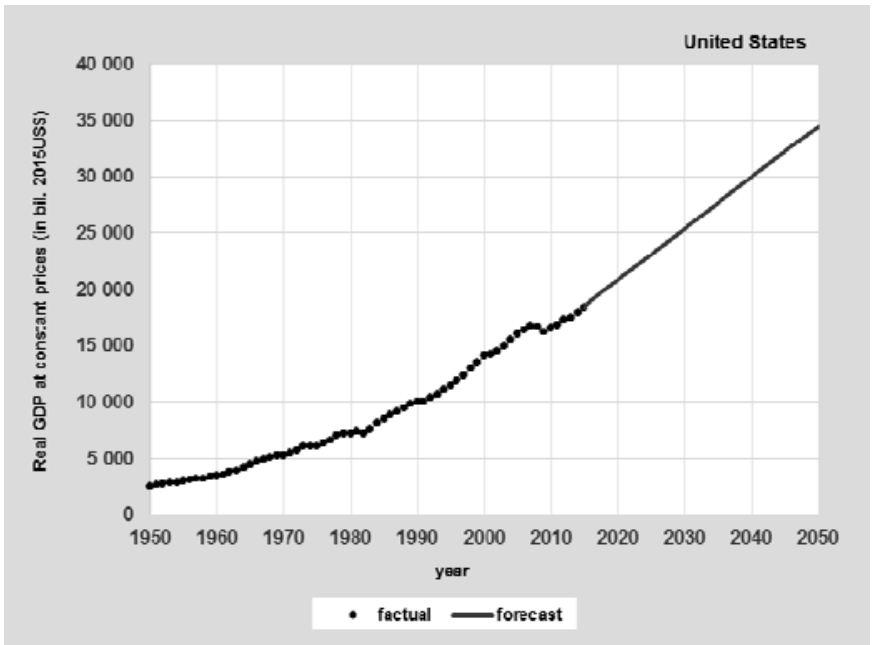

Fig. 9. Dynamics of the US GDP (in comparable prices of 2015)

Formula (15) allows calculating the forecasted rates of economic growth (Fig. 10). 


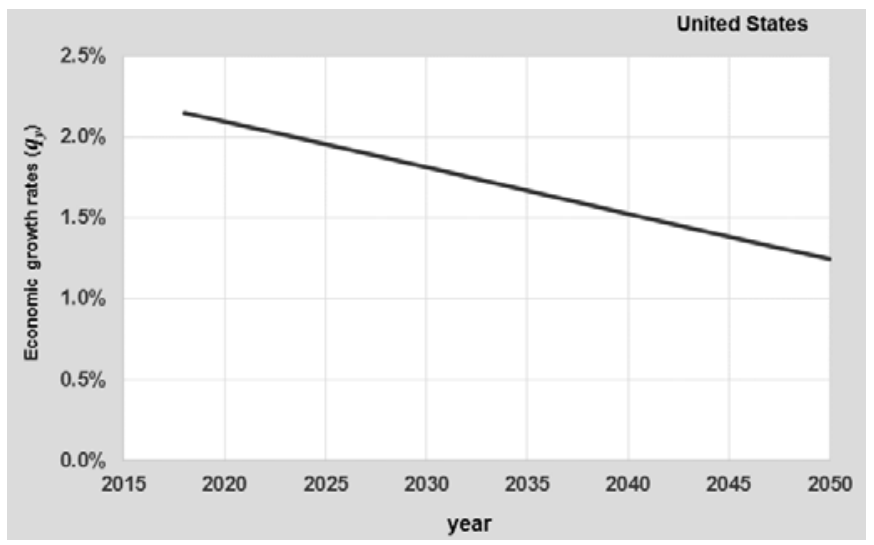

Fig. 10. Forecast of the rate of US economic growth

For making predictive employment calculations, it is first necessary to establish the trajectory of the change in the share of capital in GDP growth and to estimate the value of the parameter $\theta$.

As indicated above, the trajectory of the changing share of capital in the GDP growth is well approximated by the logistic function (formula (11)). With reference to the US economy, one can get the picture shown in Fig. 11. With respect to empirical data, our data completely correlates with other sources (e.g., Poterba 1998).

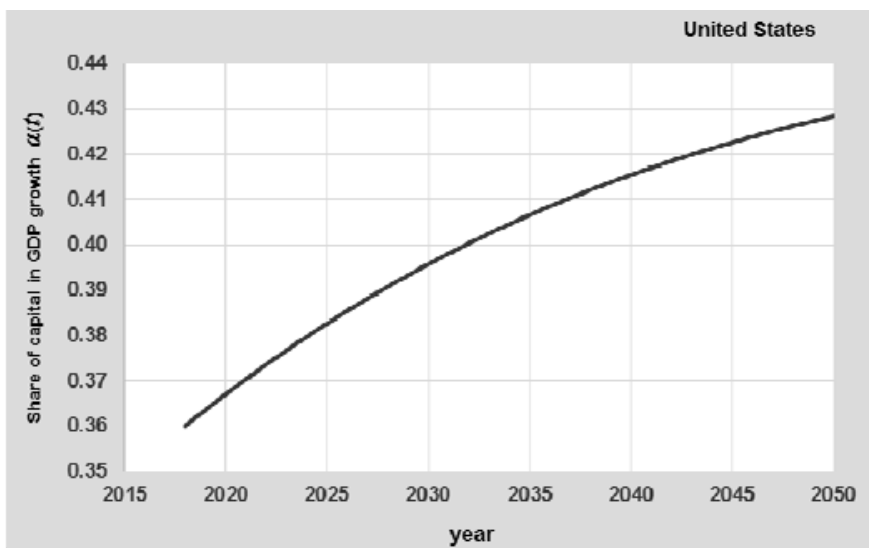

Fig. 11. Forecast of changes in the share of capital in GDP growth in the US

The parameter $\theta$ estimation is performed according to the data of the retrospective period using the formula (12c), modified to the logarithmic form 


$$
\ln L(t)=\frac{\ln \kappa}{(1-\theta) \cdot(1-\alpha+\sigma)}+\frac{1-\alpha-\theta \cdot(1-\alpha+\sigma)}{(1-\theta) \cdot(1-\alpha+\sigma)} \cdot \ln K .
$$

The results of this evaluation are shown in Fig. 12.

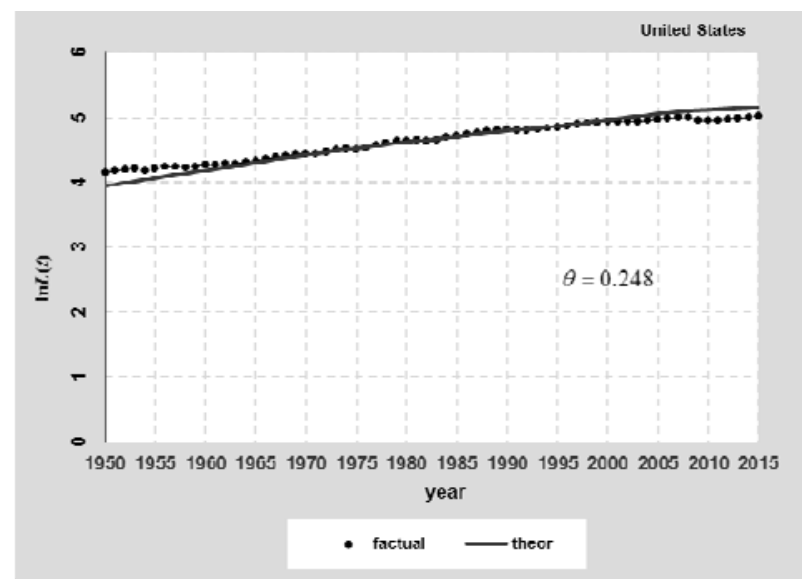

Fig. 12. Estimation of parameter $\theta$ for the US economy

Now, according to the basic formula (12c), one can obtain a forecast of employment, which, together with the retrospective data, is shown in Fig. 13.

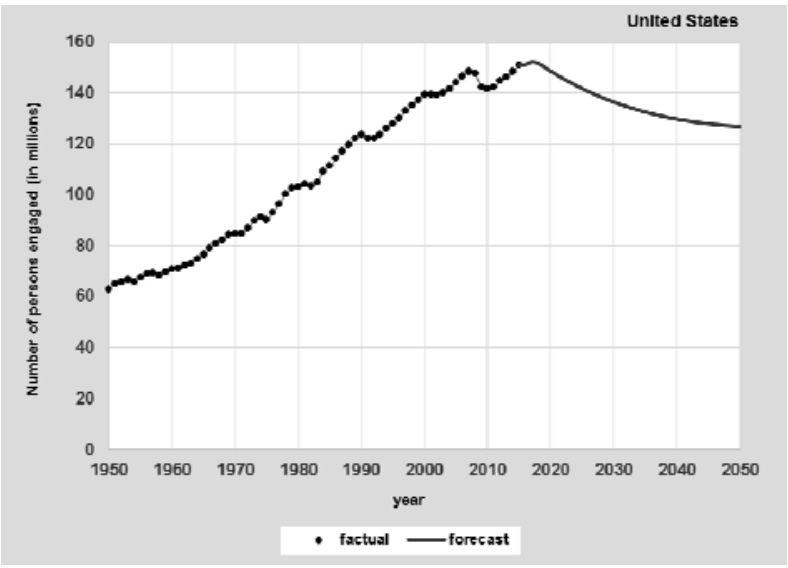

Fig. 13. Dynamics of employment in the US economy

Finally, formula (12d) allows us to construct a forecast of technical progress, which can be numerically represented by the basic rates of growth of multifactor productivity (Fig. 14). 


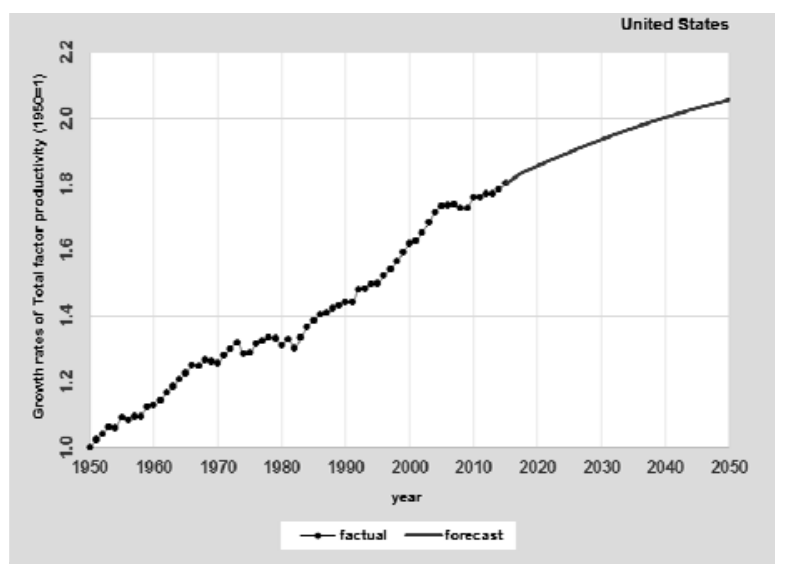

Fig. 14. Technical progress in the US economy

The main text of our study contains the results of calculations for the model for the United States. Graphical representation of the corresponding results for the remaining four countries (Great Britain, France, Japan, and China) are shown in Appendix 1. The final results of the forecast calculations in numerical form are presented in Appendix 2.

\section{INTERPRETATION OF THE RESULTS AND CONCLUSIONS}

1. First of all, it should be noted, that Piketty's assumption that the ratio between capital and output will grow is not confirmed. Our calculations show that this ratio in the period of 1950-2050, i.e. the course of 100 years will practically remain unchanged for all industrially developed countries. The only exception is China, but this is due to the low starting point of 1950 .

2. The forecast on the number of employees looks extremely alarming - the reduction can be from 16 to 29 per cent and only for the Chinese economy the picture is positive, with growth forecasted at 10 per cent. Despite the entire conditional character of the long-term forecast, we must be prepared for the most pessimistic options. There are serious reasons for that. If someone had predicted in 1970 that the number of employed in the US manufacturing industry would be reduced by 40 per cent in thirty years, this would only provoke a laugh. Yet, it happened: the number of employed decreased from 19.2 million people in March 1980 to 11.4 million in February 2010 (Glaser 2017). Obviously, such a reduction in the number of employed was primarily due to the export of capital and the creation of new industries in countries with cheaper labor, and not because of the use of industrial robots. However, the prospects of a new wave of robotics 
should not be underestimated. Thus, the trend already outlined in the widespread use of industrial robots with artificial intelligence elements can create a situation where one robot can replace 3.2 to 5.4 workers (Acemoglu and Restrepo 2017). One can assume that with the beginning of a new machine era, not only technologies but also institutional factors will change, especially in the field of labor regulation in order to provide greater opportunities for 'individualizing' the nature of work of hired workers (flexibility of working time, the ability to work remotely, perform work for several employers, etc.). If such measures are taken, it is quite possible that the picture with employment will not be as depressing as the forecast shows.

3. The relatively low rates of economic development (1-2 per cent) will become a common trend for all countries, although the volume of production will grow on a significant scale. We suggest that the main tool for the formation and satisfaction of consumer demand will be its 'personalization', which will significantly change the behavior and strategies of producers.

4. The image of the increase in the share of capital in GDP growth and the decrease in the share of labor becomes clearly pronounced. It is this tendency that should predetermine a policy of increasing spending on the maintenance and development of human resources (training, retraining, health and medical care) and stimulating the creation of jobs with a high degree of intellectual activity.

\section{ACKNOWLEDGMENT}

This article was prepared under financial support of the Russian Science Foundation (Grant No. 18-18-00099).

\section{REFERENCES}

Acemoglu, D., and Restrepo, P. 2017. Robots and Jobs: Evidence from US Labor Markets. URL: https://economics.mit.edu/files/12763.

Akaev, A., and Rudskoi, A. 2016. Economic Potential of Breakthrough Technologies and its Social Consequencts. In Devezas, T., Leitao, J., and Sarygulov, A. (eds.), Industry 4.0 - Entrepreneurship and Structural Change in the New Digital Landscape (pp. 13-41). Springer Verlag.

Ando, A., Christelis, D., and Miyagawa, T. 2003. Inefficiency of Corporate Investment and Distortion of Savings Behavior in Japan. NBER Working Paper 9444. URL: http://www.nber.org/papers/w9444.pdf.

Arrow, K. 1962. The Economic Implications of Leaning-by-doing. Review of Economic Studies 29 (80): 155-173.

Arthur, W. B. 1996. Increasing Returns and the New World of Business. Harvard Business Review 74 (4): 100-109. 
Benigno, G., and Fornaro, L. 2015. Stagnation Traps. Paper presented at the IMF Conference on Secular Stagnation, Growth, and Real Interest Rate held at Florence, Italy on June 18-19, 2015. URL: https://papers.ssrn.com/sol3/ papers.cfm?abstract id $=2938211$.

Evans, P. C., and Annunziata, M. 2012. Industrial Internet: Pushing the Boundaries of Minds and Machines. URL: https://www.ge.com/docs/chapters/ Industrial_Internet.pdf.

Hayashi, F. 2006. The Over-Investment Hypothesis. In Lawrence R. Klein (ed.), Long-Run Growth and Short-Run Stabilization: Essays in Memory of Albert Ando. Cheltenham, Glos.: Edward Elgar.

Glaser, A. 2017. Why Manufacturing Jobs are Coming Back to the U.S. - Even as Companies Buy More Robots. But for How Long? URL: https://www.recode. net/2017/5/26/15656120/manufacturing-jobs-automation-ai-us-increase-robotsales-reshoring-offshoring.

Kagermann, H., Wahlster, W., and Helbig, J. 2013. Recommendations for Implementing the Strategic Initiative INDUSTRIE 4.0. Frankfurt/Main. URL: $\mathrm{http} / /$ www.acatech.de/fileadmin/user_upload/Baumstruktur_nach_Website/Aca tech/root/de/Material_fuer_Sonderseiten/Industrie_4.0/Final_report_Industrie_ 4.0_accessible.pdf.

Kaldor, N. 1961. Capital Accumulation and Economic Growth. In Lutz, F., Hague, D. (eds.), The Theory of Economic Growth (pp. 177-222). New York: St. Martin's Press.

Miyagawa, T., Takizawa, M., and Tonogi, K. 2016. Declining Rate of Return on Capital and the Role of Intangibles in Japan. RIETI (The Research Institute of Economy, Trade and Industry). Discussion Paper Series 16-E-051, March. URL: http://www.rieti.go. jp/jp/publications/dp/16e051.pdf.

Piketty, T. 2014. Capital in the Twenty-First Century. Cambridge and London Harvard University Press.

Poterba, J. M. 1998. The Rate of Return to Corporate Capital and Factor Shares: New Estimates Using Revised National Income Accounts and Capital Stock Data. Carnegie-Rochester Conference Series on Public Policy, Elsevier 48 (1): 211-246. URL: http://piketty.pse.ens.fr/files/Poterba98.pdf.

Russel, S. J., and Norvig, P. 2003. Artificial Intelligence: A Modern Approach. $2^{\text {nd }}$ ed. Upper Saddle River, New Jersey: Prentice Hall.

Schwab, K. 2016. The Fourth Industrial Revolution: What it Means, how to Respond. URL: https://www.weforum.org/agenda/2016/01/the-fourth-industrialrevolution-what-it-means-and-how-to-respond/.

Summers, L. H. 2014. U.S. Economic Prospects: Secular Stagnation, Hysteresis, and the Zero Lower Bound. Business Economics 49 (2): 65-73. URL: http:// larrysummers.com/wp-content/uploads/2014/06/NABE-speech-Lawrence-H.Summers1.pdf.

Swan, M. 2012. Sensor Mania! The Internet of Things, Wearable Computing, Objective Metrics, and the Quantified Self 2.0. J. Sens. Actuator Netw. 1: 217-253. URL: http://www.mdpi.com/2224-2708/1/3/217. 
Graphical interpretation of calculations by model for other countries

a) Preliminary processing of source data
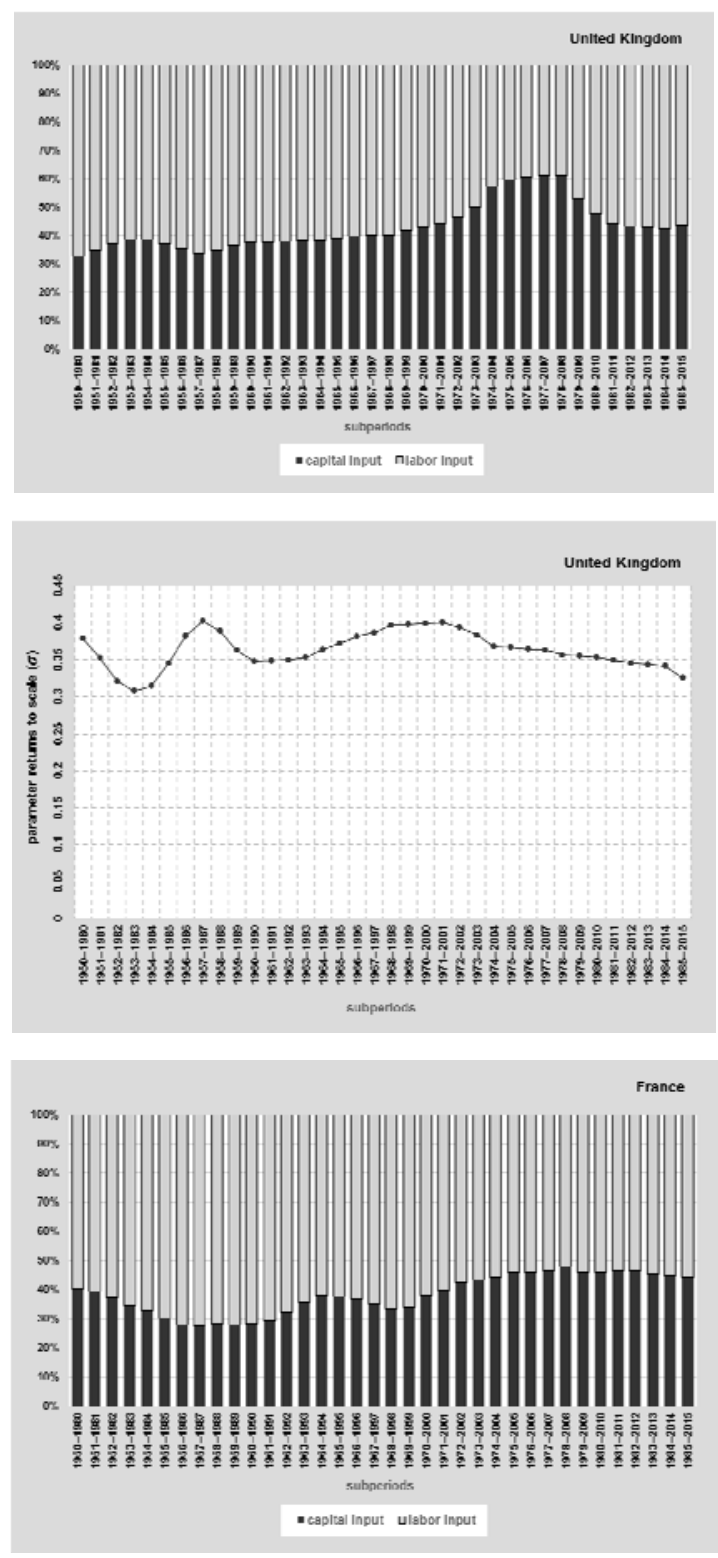

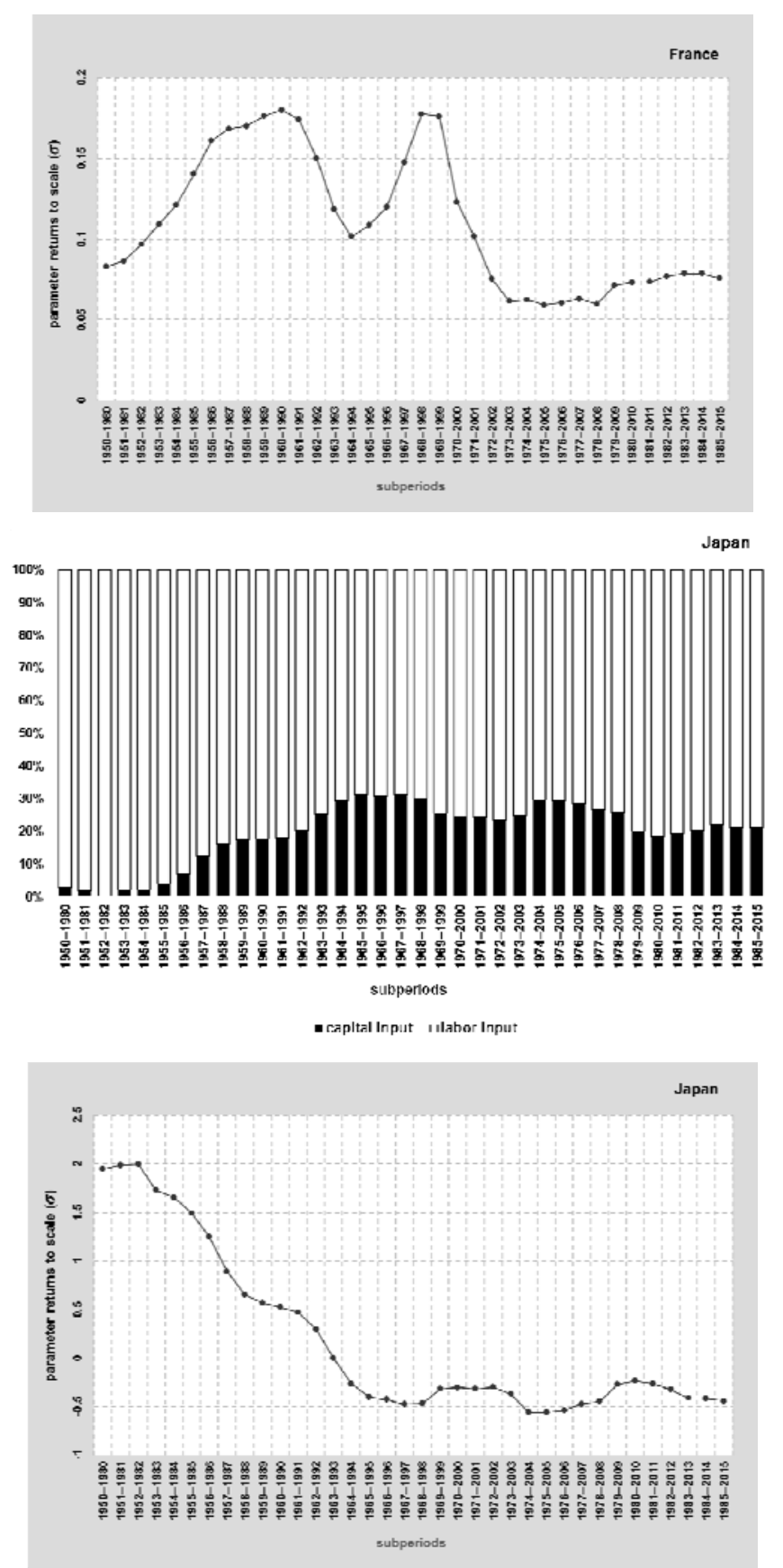

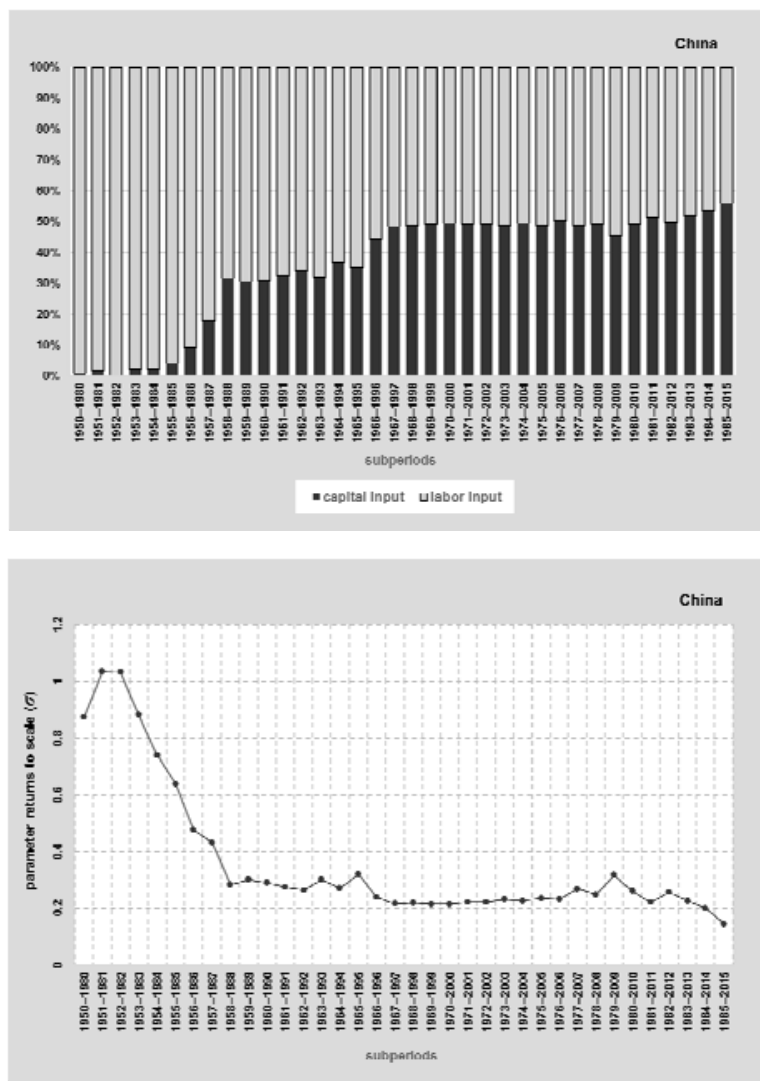

b) Dynamics of the volume of physical capital ${ }^{5}$

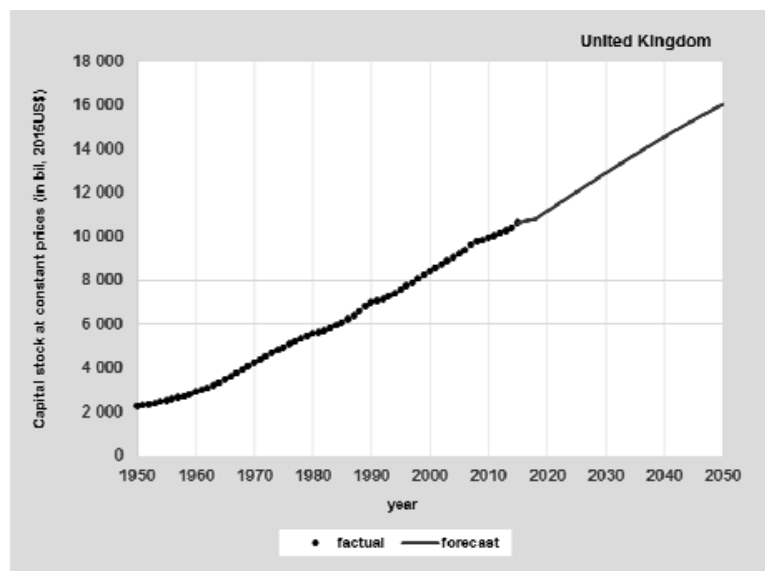



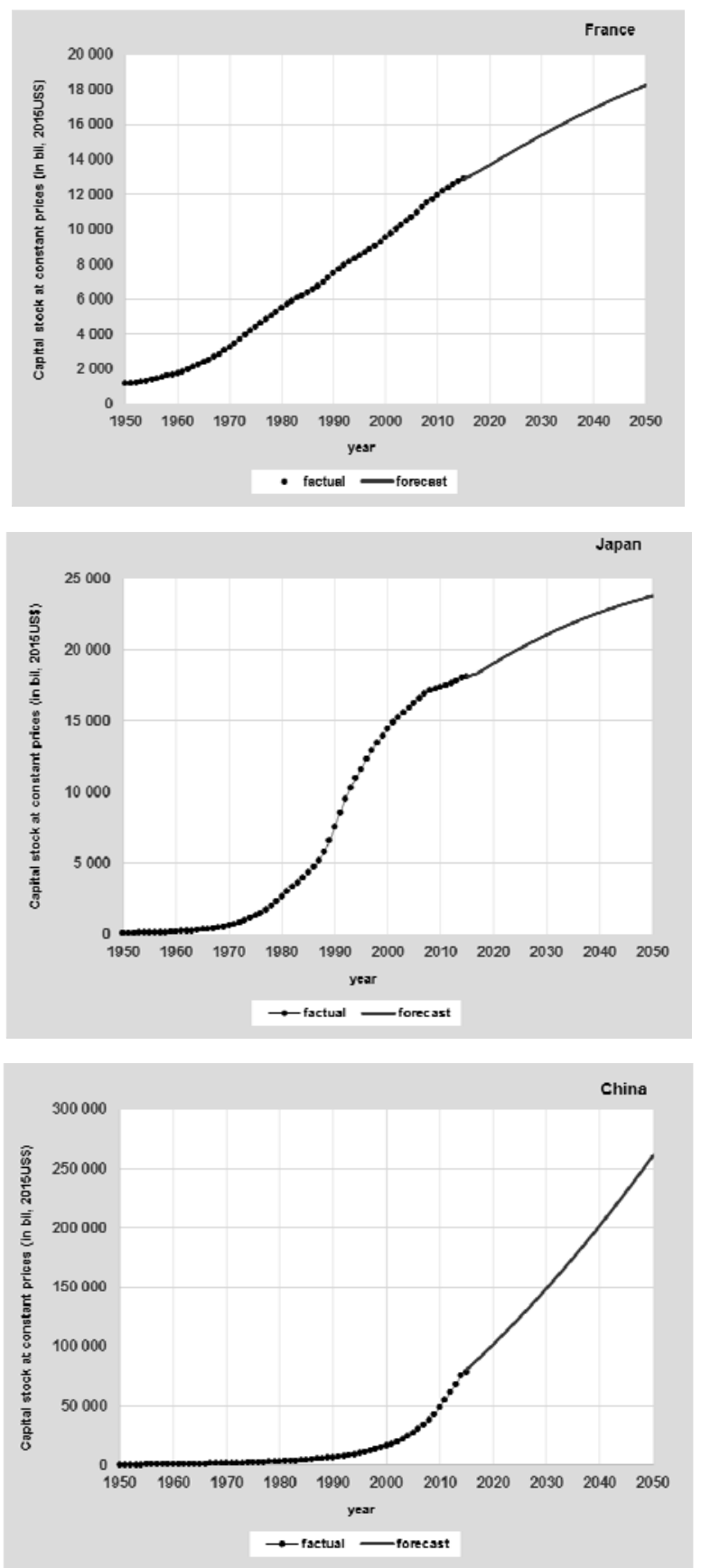
90 Social Evolution \& History / March 2019

c) Dynamics of the volume of GDP 6
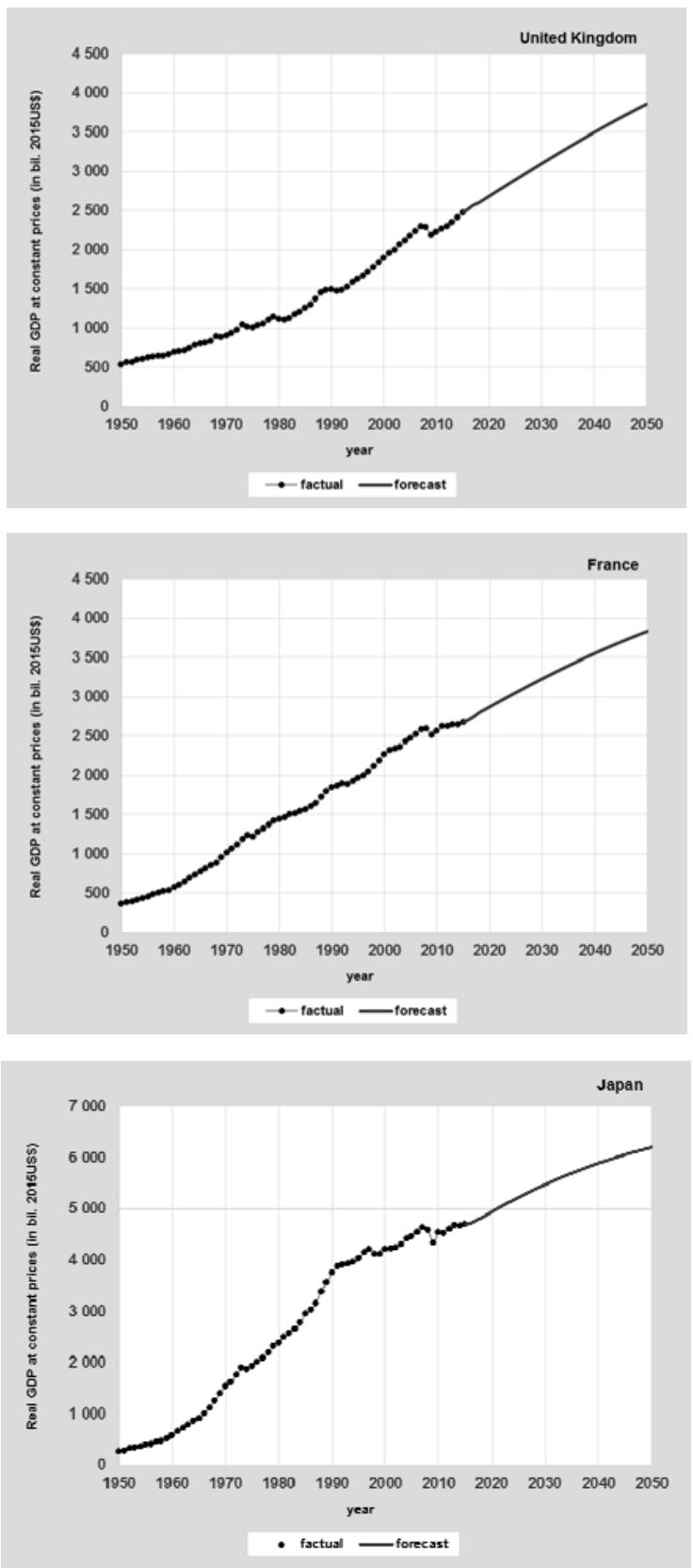


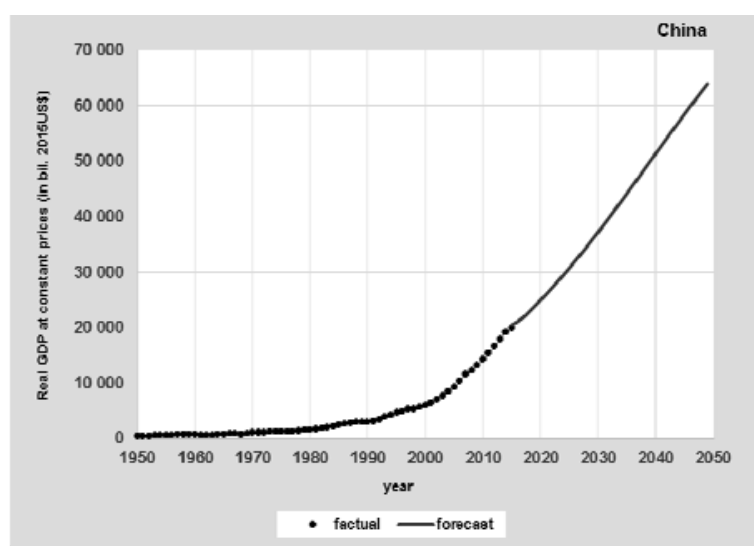

d) Dynamics of employment
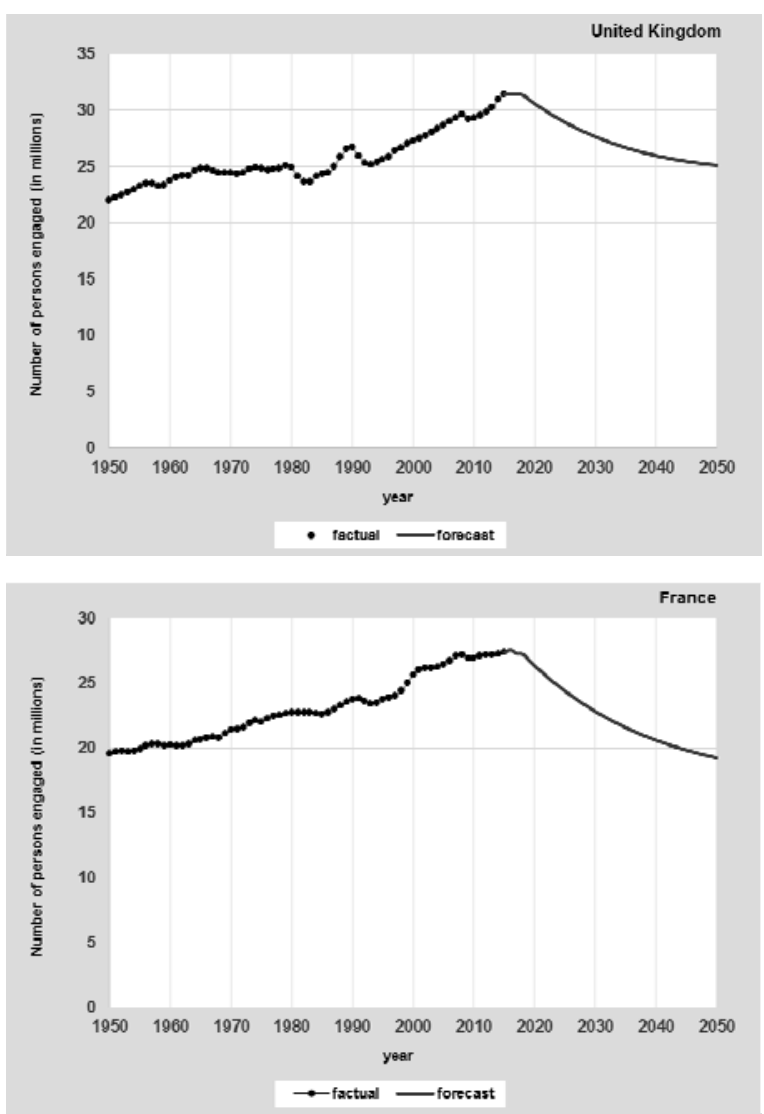

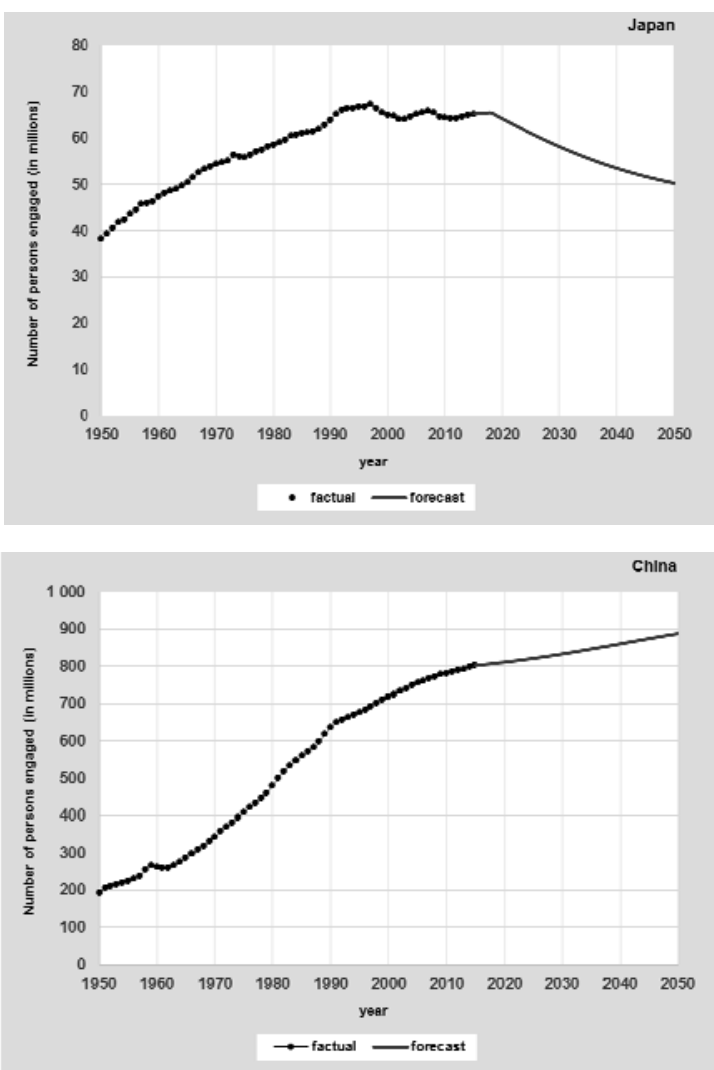

e) Forecast of economic growth rates

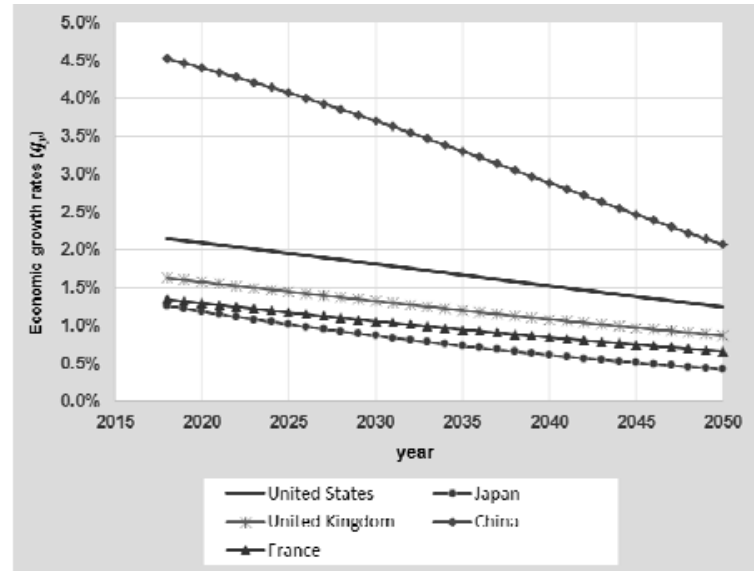


Appendix 2

\section{Results of forecast calculations}

The forecast of the volume of physical capital, billion $\$^{7}$

\begin{tabular}{|l|c|c|c|c|c|}
\hline Country & 2018 & 2020 & 2030 & 2040 & 2050 \\
\hline United States & 62,568 & 65,280 & 79,373 & 93,783 & 107,700 \\
\hline United Kingdom & 10,809 & 11,161 & 12,902 & 14,549 & 16,037 \\
\hline France & 13,334 & 13,691 & 15,397 & 16,930 & 18,249 \\
\hline Japan & 18,200 & 18,651 & 20,653 & 22,220 & 23,386 \\
\hline China & 85,800 & 93,815 & 140,912 & 196,008 & 250,942 \\
\hline
\end{tabular}

The forecast of the volume of GDP, billion $\$^{8}$

\begin{tabular}{|l|l|l|l|l|l|}
\hline Country & 2018 & 2020 & 2030 & 2040 & 2050 \\
\hline United States & 20,022 & 20,890 & 25,399 & 30,011 & 34,464 \\
\hline United Kingdom & 2,598 & 2,683 & 3,101 & 3,497 & 3,854 \\
\hline France & 2,800 & 2,875 & 3,233 & 3,555 & 3,832 \\
\hline Japan & 4,827 & 4,946 & 5,477 & 5,893 & 6,202 \\
\hline China & 21,879 & 23,923 & 35,933 & 49,982 & 63,990 \\
\hline
\end{tabular}

The forecast of economic growth rates, per cent

\begin{tabular}{|l|l|l|l|l|l|}
\hline Country & 2018 & 2020 & 2030 & 2040 & 2050 \\
\hline United States & 2.1 & 2.1 & 1.8 & 1.5 & 1.2 \\
\hline United Kingdom & 1.6 & 1.6 & 1.3 & 1.1 & 0.9 \\
\hline France & 1.3 & 1.3 & 1.1 & 0.8 & 0.7 \\
\hline Japan & 1.3 & 1.2 & 0.9 & 0.6 & 0.4 \\
\hline China & 4.5 & 4.4 & 3.7 & 2.9 & 2.1 \\
\hline
\end{tabular}

The forecast of the number of employees, million persons

\begin{tabular}{|l|c|c|c|c|c|}
\hline Country & 2018 & 2020 & 2030 & 2040 & 2050 \\
\hline United States & 152 & 148 & 136 & 130 & 127 \\
\hline United Kingdom & 31 & 31 & 28 & 26 & 25 \\
\hline France & 27 & 26 & 23 & 21 & 19 \\
\hline Japan & 65 & 64 & 58 & 54 & 50 \\
\hline China & 807 & 811 & 833 & 861 & 888 \\
\hline
\end{tabular}

The rate of change in the number of employed, from 2018, per cent

\begin{tabular}{|l|c|c|c|c|c|}
\hline Country & 2018 & 2020 & 2030 & 2040 & 2050 \\
\hline United States & 100 & 98 & 90 & 86 & 84 \\
\hline United Kingdom & 100 & 98 & 88 & 83 & 80 \\
\hline France & 100 & 97 & 84 & 76 & 71 \\
\hline Japan & 100 & 98 & 89 & 82 & 77 \\
\hline China & 100 & 100 & 103 & 107 & 110 \\
\hline
\end{tabular}

